Session 3449

\title{
A Case Study of Faculty Collaboration to Implement a Simultaneous Engineering Oriented Curriculum
}

\author{
Radha Balamuralikrishna, Andrew Otieno \& Abul Azad \\ Northern Illinois University \\ DeKalb, IL 60115, USA \\ Email: bala@ceet.niu.edu, otieno@ceet.niu.edu, azad@ceet.niu.edu
}

\section{Introduction}

Educational initiatives that particularly reflect the paradigm of simultaneous engineering are encouraged by the College of Engineering and Engineering Technology at Northern Illinois University (NIU) ${ }^{1}$. The NIU engineering technology programs under the auspices of the department of technology provides for two areas of specialization, Electrical Engineering Technology (EET) and Manufacturing Engineering technology (MET). The department also offers a degree in the industrial technology track. In the year 2002, the University's Committee for the Improvement of Undergraduate Education supported the authors' joint proposal to challenge engineering and industrial technology students enrolled in three different courses to complete an interdisciplinary project towards part-fulfillment of their course requirements. This paper presents a comprehensive view of this case study highlighting the relevance of the project, logistics, and outcomes both from the perspective of students and the authors. This presentation will also focus on the challenges of conducting such collaborative projects and recommend dos and don'ts for faculty teams that plan to conduct interdisciplinary student projects in engineering technology.

\section{Relevance of Interdisciplinary Projects and Fostering Student Collaboration}

In recent decades there has been an increasing demand on manufacturers to reduce the cycle time for new product development. At the same time, we continued to see that the life cycle of new products became increasingly shorter. In this era of a free global market economy that fosters and nurtures creativity as well as innovation, engineering technologists can rest assured that these observations define a trend that will continue into the coming decades at an even more furious pace. The philosophy of simultaneous engineering is principally geared towards accelerated product development through intelligent teamwork and a networking of interdisciplinary teams. Educational programs oriented institutions such as the Accreditation Board for Engineering and Technology (ABET) and the Society of Manufacturing Engineers (SME) have either directly or indirectly proclaimed that undergraduates in our discipline should be well prepared in all aspects of teamwork and possess a certain degree of breadth and depth of exposure to various bodies of engineering that are exemplified in present day machines and consumer products ${ }^{2}$. 
The SME study noted that fresh graduates in manufacturing were particularly lacking in "their ability to recognize other's contributions and to draw from fellow team members knowledge and expertise ${ }^{2, \text { p. } 27 " . ~ T h e ~ s a m e ~ s t u d y ~ a l s o ~ i d e n t i f i e d ~ a ~ f a c t o r ~ c a l l e d ~ " p e r s o n a l ~ a t t r i b u t e s " ~ w h i c h ~ w a s ~}$ deemed a core competency for manufacturing graduates. Some of the major elements defining personal attributes were identified as leadership qualities, sensitivity to others, professionalism, integrity, a consciousness of the enterprise as a whole, global awareness, an ability to both teach and learn from others, analytical skills, consensus building, and personal responsibility ${ }^{2}$. These findings should inform the intuitive educator that the goals for manufacturing education in the $21^{\text {st }}$ century can not be met using familiar old approaches exemplified by the teacher-centered model with a predominant emphasis on lectures, tests and exams. On the other hand, the approach should be student centered with greater emphasis on design projects, teamwork, and relevance to industry.

We are well aware that the concept of interdisciplinary projects is not a new idea in engineering or engineering technology. A significant number of educator teams have successfully conducted interdisciplinary projects at institutions both in the United States and abroad. In the early 1990s, Jeffries emphasized how simultaneous engineering was fast becoming an agent for sweeping reforms in manufacturing education ${ }^{3}$. Kitto provided an excellent insight into the blending of simultaneous engineering practices in engineering and industrial technology education at Western Washington University ${ }^{4}$. The integrated product and process development paradigm of simultaneous engineering has positively impacted manufacturing education in countries such as Australia, Brazil, China, and Japan in recent years ${ }^{5-8}$. The Hong Kong University of Science and Technology administers a highly successful integrated manufacturing program that emphasizes both teaching and research ${ }^{9}$. A successful engineering technology program should be aligned with needs of the industry; this was the primary motivating force urging the authors to collaborate and conceive an interdisciplinary project. The successful experiences of other pioneers in this area were without question, another encouraging factor.

\section{Student Projects}

Students enrolled in selected courses that the collaborating faculty members offered during the Fall 2002 semester were challenged to work cooperatively on a project of their choice. The stipulated requirement for the project was that it had to contain at least one major component that would require utilization of skills derived from each of the three courses taken. Table 1 shows the dispersion of student enrollment for each of the targeted course.

Table 1. Student Enrollment in the Three Courses Selected for the Study

\begin{tabular}{|l|l|l|}
\hline Course Number and Title & \# of students & Predominant Major \\
\hline TECH 414. Computer-Aided Machine Design & 9 & Industrial Technology \\
\hline TECH 420. Computer Integrated Manufacturing & 12 & Manuf. Engg. Tech. \\
\hline TECH 430T. Microcontrollers Interfacing and Applications & 30 & Elec. Engg. Tech. \\
\hline
\end{tabular}

After an availability survey was carried out in the three classes, nine student teams were formed. Each team was required to submit a proposal to complete an integrated project by the end of the third week of the semester. The authors approved the proposals after due consideration of the scope of the project and its feasibility in terms of the available resources. Project teams continued to present progress reports on a weekly basis and received assistance from the faculty

Proceedings of the 2003 American Society for Engineering Education Annual Conference and Exposition Copyright (C) 2003, American Society for Engineering Education 
team as required. Students were required to demonstrate the working project and present them orally at the end of the semester, and in addition, submit a detailed written report. Brief descriptions of each of these projects along with useful illustrations are presented here.

\section{Project 1: Design and development of a MC Hopper}

The need for speed is a big part of many athletic/sporting events and past times. The sport of paintball is no different. Paintball guns can shoot as fast as the person pulls the trigger, but paintballs can only fall as fast as gravity. Electronic paintball hoppers made the sport of paintball a fast paced game that makes the possibilities of paintball guns technology even higher. The system comprised of a microcontroller board, motor and ball system, LCD display, and an electronic interface between the LCD and system, and a container. Figure 1 shows a prototype of the system. Considering the limited duration of the project, the group could not manage to put the entire system together, however, they managed to demonstrate their working concepts.
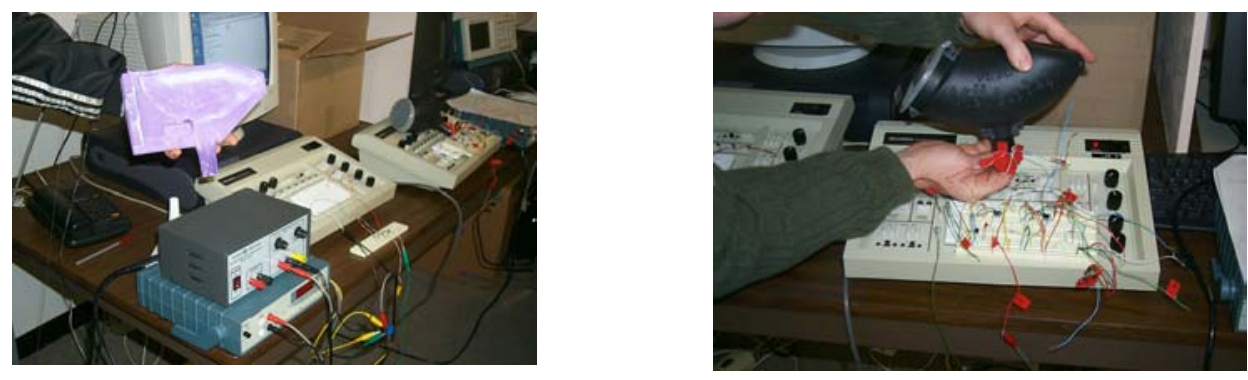

Figure 1: Prototype for the MC Hopper system.

Project 2: Design of a safe-room within a house.

The safe room is a hidden room that will protect a family or its members in case of any threat from an intruder. For the designed system there will be several safety switches around the house mainly with doors and windows. If there is an intrusion at any of those points an indicator will glow. At this point the family members can move into the safe room and the door of the room will be locked automatically and allow the members to take action to contact the outside world. The designed system consists of a sensing system (door contacts, motion detectors, window sensors, glass breaking sensors) along a motor control system for door movement. The system is powered through a solar cell and backup battery. The picture of the developed system is shown in Figure 2.
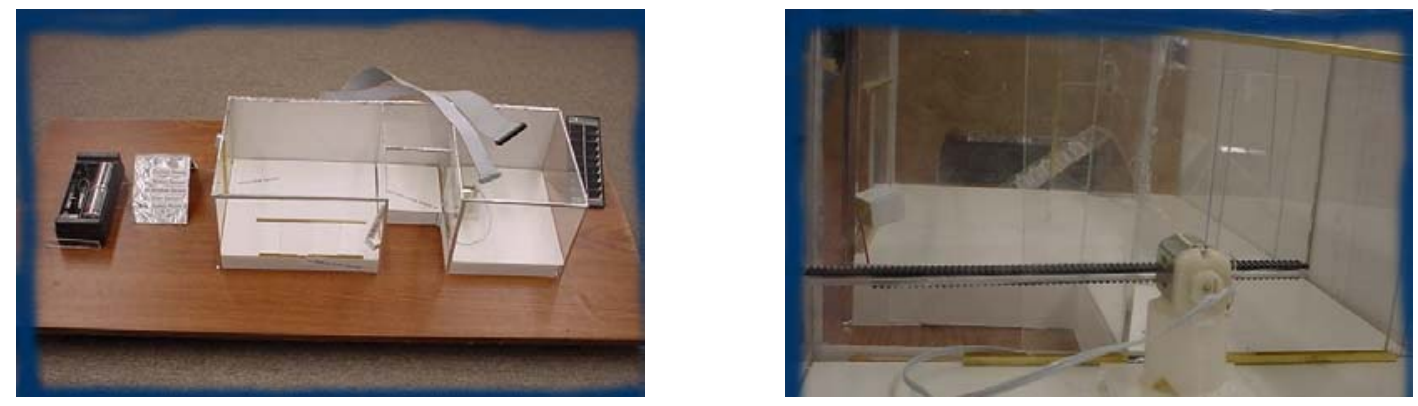

Figure 2: Prototype of the safe room system. 


\section{Project 3: Motorcycle gear position indicator}

The typical motorcycle has 5 or 6 forward gears. However, for the rider the only indication of what gear the bike is presently is the neutral light, which illuminates only when neutral is selected. Due to lack of any indicator, there is no certain way to know what gear the motorcycle is in unless the rider mentally keeps tracks of this. However, keeping track of the gear position is important especially for the novice rider and also helpful in learning what gears corresponds to what engine rpm and road speed. With the developed device, the rider will be able to identify the current gear position through a set of LED indicators. The system consists of a microcontroller system, gear switching box and a suitable interfacing circuit. Figure 3 shows the components of the project.
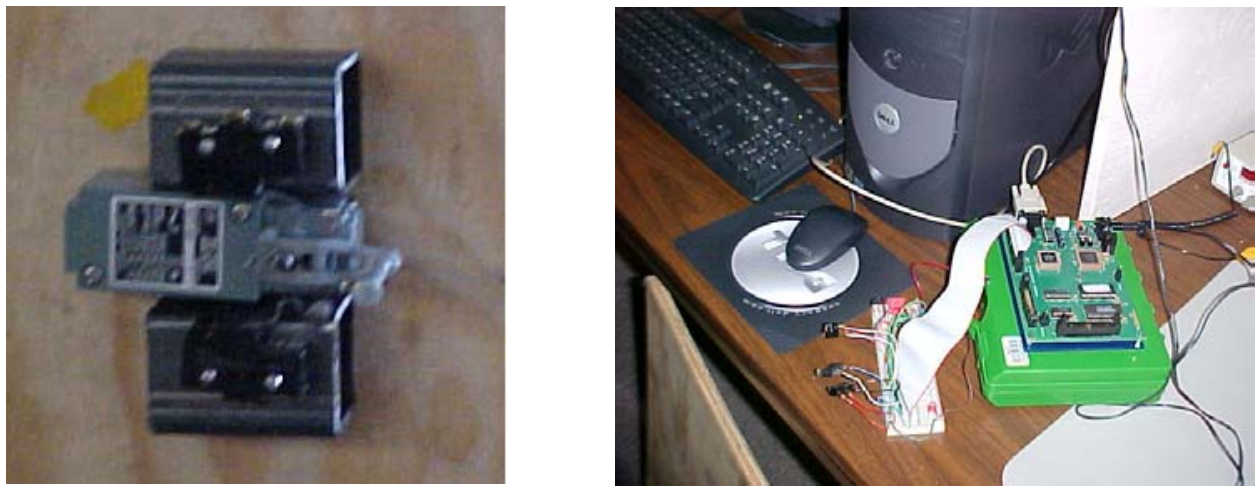

Figure 3: Components of motorcycle gear detection system.

\section{Project 4: Alternative powered vehicle}

This project involved converting a $500 \mathrm{cc}$ gasoline driven Yamaha motorcycle into a 24-volt electrical powered machine. Extensive work was needed to convert the mechanical system of the motorcycle for the new powering system. This involved the design and construction of a drive train system. To provide variable speed an electronic controller board was utilized along with a microcontroller system. Figure 4 illustrates the designed system.

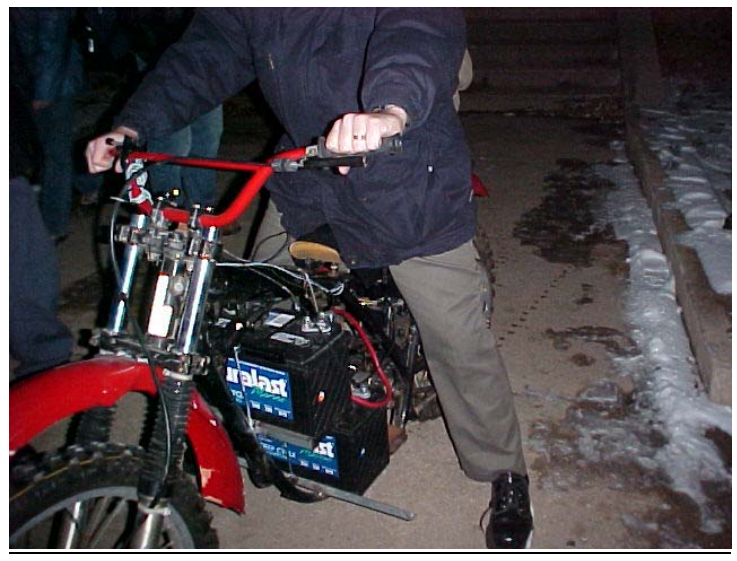

Figure 4. Redesigned Motorcycle 


\section{Project 5: Active headlight system for an automobile.}

The purpose of this project was to improve driving visibility at night on unpaved roads and during off-read conditions. On rough terrain, conventional headlight systems are often ineffective. The light beam emitted illuminates in the direction of inclination of the car. This also means if a sudden dip is encountered the front, the headlights of the car will be momentarily pointing to the ground. Likewise, if a bump is encountered, the headlights will be momentarily pointing upwards. The active headlight system conceived in this project should automatically adjust the light direction for the above conditions and improve the visibility dramatically at night. The designed system consists of a servo system, level sensor, interfacing electronics and digital controller system. Figure 5 illustrates a prototype of the system.
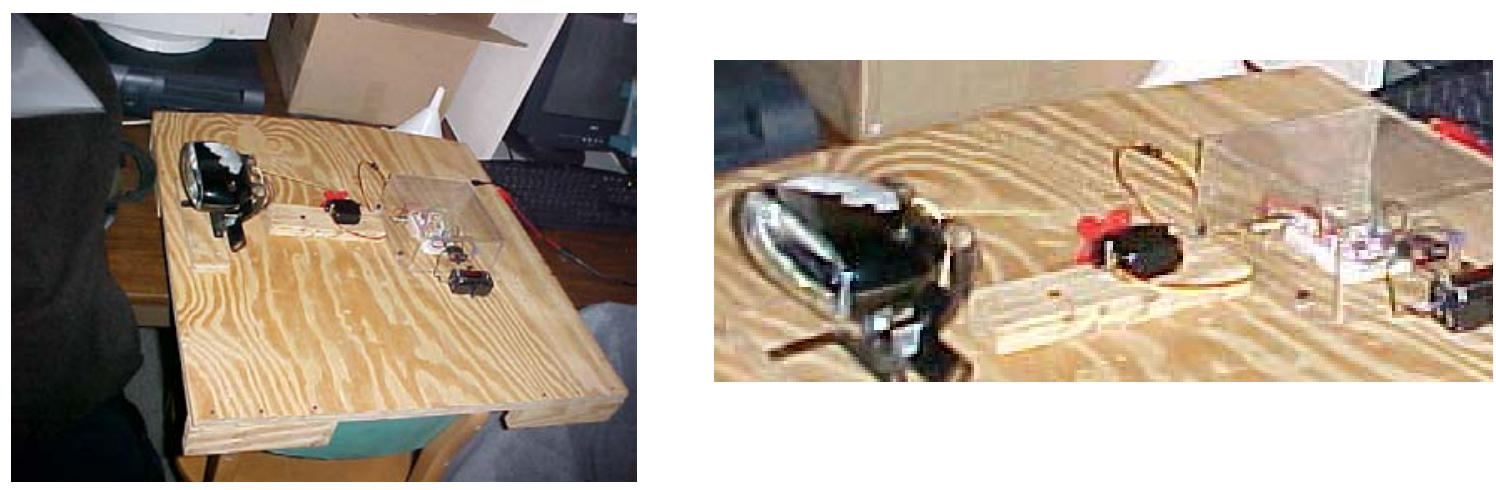

Figure 5: Prototype of the active headlight system

\section{Project 6: Smart garage}

The smart garage system involves the identification of various incoming vehicles for a household and takes some action accordingly. For any identified vehicle, the driveway light will be lit for a period of time. If a vehicle is for the household, then the garage door will be opened automatically. In addition, the system will close the door automatically, heating the garage on time. An in-depth monitoring board is included, which can be set by the homeowner. The designed system consists of a sensor-interfacing system along with a bar-code reader. Figure 6 below shows a PLC controlled workbench that was used to simulate the operation of the system. 


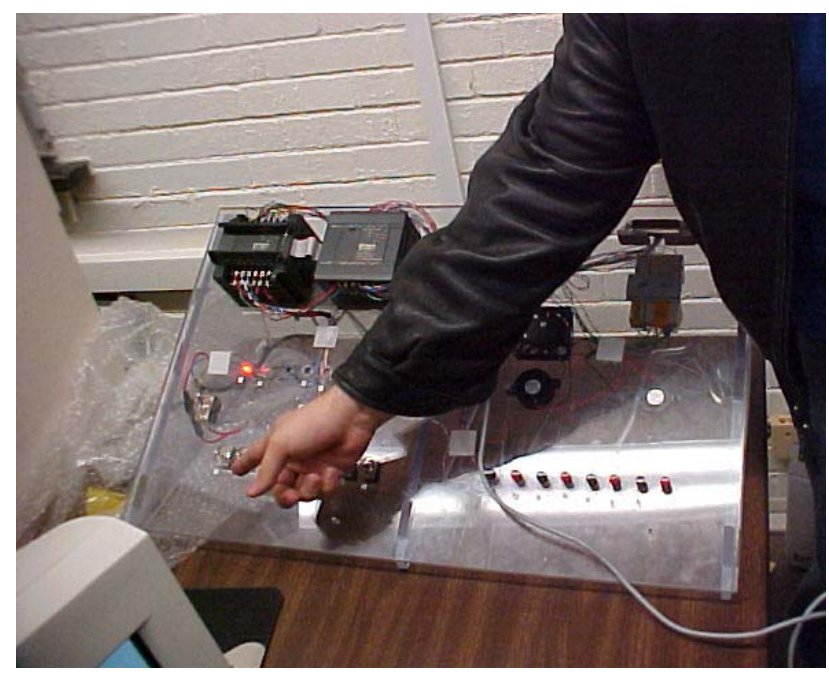

Figure 6. A simulation of the smart garage

\section{Project 7: Automated pill dispenser}

The pill dispenser delivers the prescribed number of pills at any specified time. The systems consisted of a pill container that has six different compartments all spanning around a motor shaft that will drive the lid. At the appropriate time a buzzer will sound and a green light would come on to let the consumer know that it is time to take the next dose. Once the switch is pushed, a buzzer and the green lights would go off and the lid will rotate allowing the pills to drop out a hole under the container from the next compartment in line. The developed system contained a PLC timer, motor drive system, dispensing unit and an indication system. A prototype of this project is shown in Figure 7.

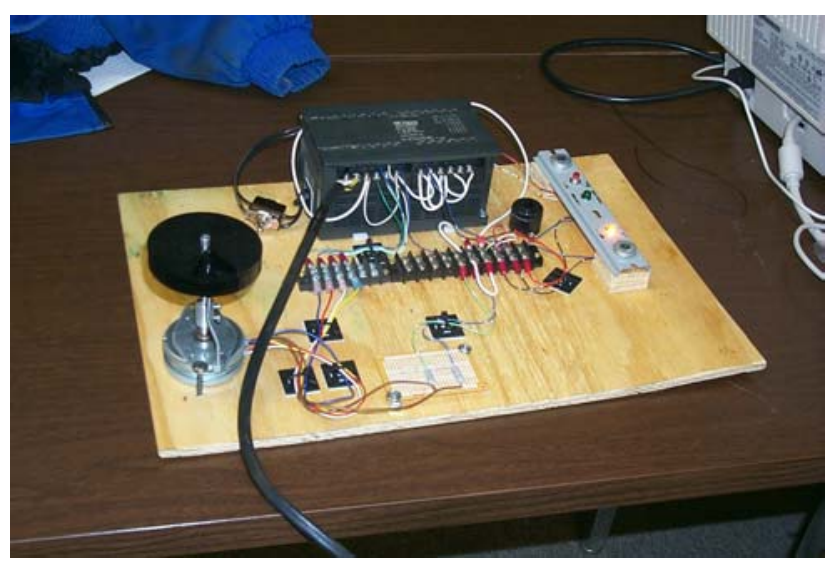

Figure 7: Prototype of the automatic pill dispensing system

Project 8: Automatic obstacle detection system 
This system is intended to warn a driver when a car is too close to an object and hence avoid accidental collisions. The driver can set the exact distance as needed. The warning may be a flashing light or a digital readout displaying distance. The automobile will be fitted with two sensors, one at the front and other at the back. The designed system consisted of a sensor, interfacing unit, and a microcontroller system for the control. Pictures of a prototype of the system are shown in Figure 8.
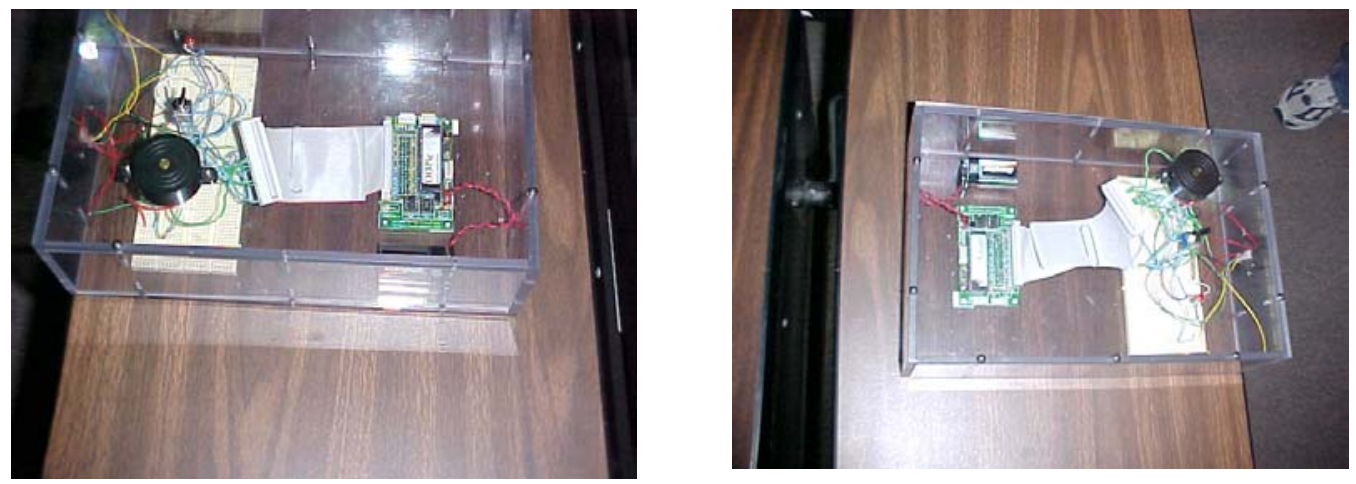

Figure 8. Prototype of the automatic obstacle detection system

Project 9: Light intensity control with the daylight

The objective of this project was to design a system, which could control the light intensity within a room according to the amount of daylight. This would minimize the energy cost through the use of natural light. The microcontroller based system was a multi-channel light adjuster to control the brightness of light. The device would include a microcontroller system, light level sensing system with suitable interfacing with the microcontroller. The intensity of the light level decreased with increased levels of daylight and vice versa. The students managed to carry out a concept design but were not able to fabricate and implement the system.

\section{Overall observations from student projects}

The brief description of projects should be indicative of the enthusiasm, creativity, and innovativeness of the student project teams. The students were required to create solid models using a computer-aided design (CAD) system to document their design ideas. In some cases, schematic drawings were used exclusively or to augment the models. It was clear that all student projects involved a certain degree of understanding and application of automation technologies such as the use of programmable logic controllers. Microcontrollers, transducers, actuators, system controllers and electronic interfacing were used as required to realize the intended function of the designs. Each project team was required to think in terms of the system accuracy, reliability and performance in general. Simply put, the faculty team members were impressed with a majority of the student projects and acknowledged that these outcomes were made possible as a result of combined efforts of faculty and students. We strongly feel that overall the students experienced more relevant and enhanced learning through their interdisciplinary project than that would have occurred through structured and compartmentalized problem solving. 


\section{Assessment Results}

Engineering educators continue to place an increasing amount of emphasis in evaluating new ideas implemented in the classroom and alternative pedagogical practices ${ }^{10}$. Hence, assessment was an important issue in conceiving and implementing the project. The main goal of the assessment was to determine whether students participating in an interdisciplinary project with team members drawn from different classes other than their own enhanced their simultaneous oriented engineering skills. This assessment was also performed to collect data as part of our faith in a "continuous improvement paradigm" for future collaborative projects. A paper and pencil survey instrument was administered to each student at the end of the semester. The questionnaire consisted of a significant number of items in which the students were asked to rate using a scale of A (excellent or very adequate), B (good or somewhat adequate), C (average or somewhat inadequately), D (fair or very inadequately) or E (poor or does not apply). The questions asked included (i) the students' perception of how well the projects were organized by faculty, (ii) learning experiences in working with diverse teams, and (iii) how relevant and important was the knowledge gained from their individual courses to this interdisciplinary project. The questionnaire also asked the students to rate how adequately they used the following skills to accomplish the project; scientific inquiry, creative thinking at the design stage, critical thinking, science and math, synthesis of knowledge from various skills, and communication skills. The students were also required to rate how functional they thought their groups were as a team. For purposes of analysis, A is a fully functional group, B is functional, $\mathrm{C}$ barely functional and $\mathrm{D}$, not functional at all. Also in the questionnaire were other open-ended items that provided students with an opportunity to render detailed remarks about their experiences, important lessons learnt, and any changes they would like to see if they were to participate in a similar project in the future. A total of 42 students completed the survey questionnaires. Figure 9 summarizes the percentage of students that responded on the A to E scale for each of the questions asked.

From the results obtained there is a clear indication that most students had a positive learning experience in working with diverse teams to implement a project. This is a good indicator that the goals of the project were met. Most students indicated that the level of organization was good, however the majority felt it was average or fair. This can be attributed to the fact the projects had to be funded from a very tight departmental budget originating from student course fees. One of the other observations in the students' comments that also explains this is the fact that the three different classes met at different times in different days and this posed a problem for the students to arrange a common suitable time to meet, especially those in full time employment. In addition, this being the first attempt at such a venture, the rubrics for the projects were not as comprehensive as they should be to provide students with a clear understanding of what direction they ought to take for the project. Despite the organizational problems, the fact that nearly half of the groups were very functional and another $40 \%$ functional indicates that the simultaneous oriented engineering approach can be used within a limited resource environment to undertake major projects successfully. 


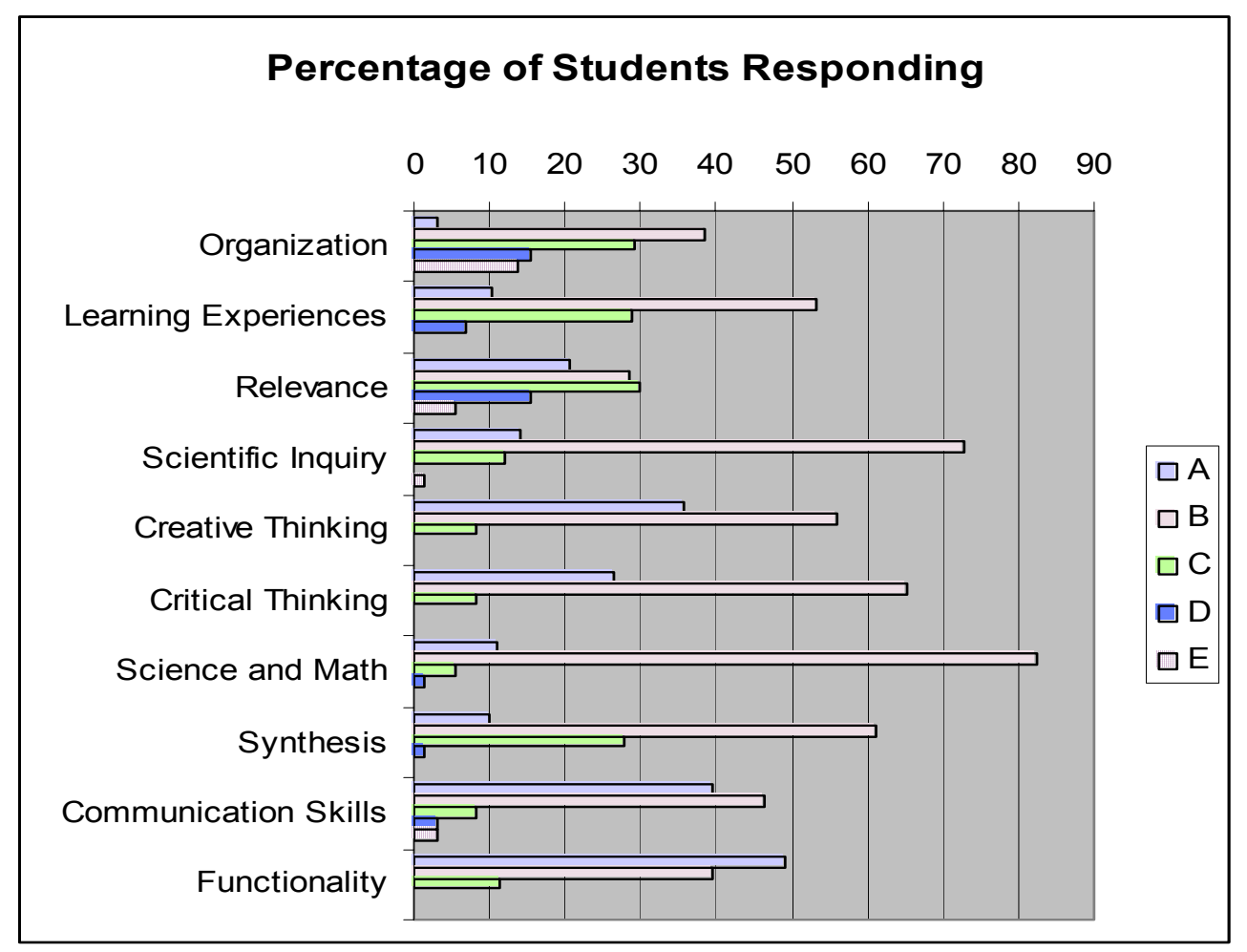

Figure 10. Results from student evaluations

The most outstanding skill requirements that scored highest in the "very adequately" category were communication skills (39\%) followed by creative thinking (36\%) and critical thinking (26\%). Indeed many students in their comments attested to the fact that either their communications skills or need for good communication skills were very important to get the teams working together. It is also evident from these results that for the successful completion of the projects, most students found their knowledge of math and science, and their scientific inquiry very adequately or adequately utilized to design and complete their projects.

Another interesting result from the assessment is the relevance of the students' individual courses to the successful completion of the project. Only $21 \%$ thought what they learnt in their courses was very relevant to this project, while about $30 \%$ felt it was relevant or fairly relevant. In contrast to this scenario, the majority of the students felt that synthesis of the various skills required for the project was very adequately $(10 \%)$ or adequately achieved. As is the case with an integrated team project, more often the team players learn from each other as they move on and this delineates the need for individualized skills while promoting synthesis of the various bodies of knowledge and this indeed is a very important aspect of simultaneous engineering.

In order to find a relationship between each of these factors, a multivariate analysis was performed on the data using SPSS. The table below shows the Pearson correlation coefficients, $r$, and level of significance, $p$, on the 2-tailed test. 


\begin{tabular}{|c|c|c|c|c|c|c|c|c|c|c|c|}
\hline & & Organ. & $\begin{array}{c}\text { Learning } \\
\text { Exp. }\end{array}$ & Relevance & $\begin{array}{l}\text { Scient. } \\
\text { Inquiry }\end{array}$ & $\begin{array}{l}\text { Creative } \\
\text { Thinking }\end{array}$ & $\begin{array}{c}\text { Critical } \\
\text { Thinking }\end{array}$ & $\begin{array}{c}\text { Science/ } \\
\text { Math }\end{array}$ & Synthesis & $\begin{array}{l}\text { Comm. } \\
\text { Skills }\end{array}$ & Function. \\
\hline \multirow[t]{2}{*}{ Organ. } & $r$ & 1.000 & $.383^{*}$ & $.536^{* *}$ & -.027 & .114 & .107 & -.065 & .062 & .146 & $468^{\star *}$ \\
\hline & $p$ & & .012 & .000 & .865 & .472 & .501 & .683 & .698 & .357 & .002 \\
\hline \multirow{2}{*}{$\begin{array}{l}\text { Learning } \\
\text { Exp. }\end{array}$} & $r$ & & 1.000 & $.385^{*}$ & .221 & .275 & .236 & .184 & $.378^{*}$ & $.451^{\star *}$ & $.525^{\star \star}$ \\
\hline & $p$ & & & .012 & .160 & .078 & .132 & .244 & .014 & .003 & .000 \\
\hline \multirow[t]{2}{*}{ Relevance } & $r$ & & & 1.000 & .053 & .195 & .225 & .234 & .114 & .070 & .279 \\
\hline & $p$ & & & & .738 & .215 & .153 & .136 & .473 & .660 & .073 \\
\hline \multirow{2}{*}{$\begin{array}{l}\text { Scient. } \\
\text { Inquiry }\end{array}$} & $r$ & & & & 1.000 & $.477^{* *}$ & $.453^{* *}$ & $.416^{\star *}$ & $.464^{* *}$ & .212 & $.360^{*}$ \\
\hline & $p$ & & & & & .001 & .003 & .006 & .002 & .177 & .019 \\
\hline \multirow{2}{*}{$\begin{array}{l}\text { Creative } \\
\text { Thinking }\end{array}$} & $r$ & & & & & 1.000 & $.631^{* *}$ & $.499^{\star \star}$ & $.428^{* \star}$ & $.344^{*}$ & $.320^{*}$ \\
\hline & $p$ & & & & & . & .000 & .001 & .005 & .026 & .039 \\
\hline \multirow{2}{*}{$\begin{array}{l}\text { Critical } \\
\text { Thinking }\end{array}$} & $r$ & & & & & & 1.000 & $.532^{\star \star}$ & $.521^{\star \star}$ & .251 & .269 \\
\hline & $p$ & & & & & & . & .000 & .000 & .109 & .084 \\
\hline \multirow{2}{*}{$\begin{array}{c}\text { Science/ } \\
\text { Math }\end{array}$} & $r$ & & & & & & & 1.000 & $.406^{* *}$ & .292 & $.306^{*}$ \\
\hline & $p$ & & & & & & & . & .008 & .060 & .049 \\
\hline \multirow[t]{2}{*}{ Synthesis } & $r$ & & & & & & & & 1.000 & $.389^{*}$ & .260 \\
\hline & $p$ & & & & & & & & . & .011 & .096 \\
\hline \multirow{2}{*}{$\begin{array}{c}\text { Comm. } \\
\text { Skills }\end{array}$} & $r$ & & & & & & & & & 1.000 & $.520^{\star \star}$ \\
\hline & $p$ & & & & & & & & & . & .000 \\
\hline \multirow[t]{2}{*}{ Function. } & $r$ & & & & & & & & & & 1.000 \\
\hline & $p$ & & & & & & & & & & . \\
\hline & & & & & & & & $\begin{array}{l}\text { led). } \\
\text { iled). }\end{array}$ & & & \\
\hline
\end{tabular}

Table 1. Pearson correlation coefficients for the various factors

From this analysis, there is a moderate positive correlation between creativity and critical thinking $(\mathrm{r}=0.632$, significant at $\mathrm{p}<0.01)$ in the development of a successful project. All projects were open-ended design problems and it is quite reasonable to assume that creativity was very important. The results also show that there was moderate positive correlation $(\mathrm{r}=0.52$, significant at $p<0.01$ ) between communication skills and group functionality. Likewise the students who had very positive learning experiences in a team-based environment showed significant correlation of this experience with communication skills. Any successful team project must rely on effective communications between team members. Moreover the success of a simultaneous engineering oriented project must rely on team members being proactive and ready to learn new skills and learn from each other. This is also shown by the fact that there was very low correlation, $\mathrm{r}=0.28$, between what the students learnt in their own courses and the successful completion of this project. In one of the comments, a student confessed that he had never learnt how to machine a part but at the end of the project he became "...an expert" in machining. Other significant correlation coefficients were identified between the use of science and math and scientific inquiry, critical thinking and creative thinking; and also between how the students synthesized the different bodies of knowledge required for the project with scientific inquiry, critical thinking, science and math and their learning experiences.

\section{Conclusion and Recommendation}

In an era of global competition, a better-educated and trained workforce will separate the winners from the losers. The future of America depends to a great extent on the quality of engineers and technologists produced at our higher educational institutions. The Technology department at NIU is proud of its role in the initiative presented in this paper. We strongly believe in the assessment component of new teaching initiatives and we hope to continue to learn from student feedback and disseminate findings for the benefit of our discipline. We also plan to 
learn from this first experience and implement better practices in future such collaborative projects. This also means that we seek to explore new ways to finance these activities through grant proposals. From our viewpoint, the efforts required in establishing meaningful faculty collaboration and then in turn overseeing the formation and maturing of student project teams is time consuming and hard work. However, this preliminary study showed strong signs that integrated design projects provided a fulfilling learning experience for students. We hope that our efforts described in this paper will motivate engineering technology educators to undertake similar initiatives at their institutions. Several parallel and replicated studies at institutions dispersed across the country should eventually confirm the effectiveness of integrated interdisciplinary projects. Educators should also continue to focus on more efficient ways of providing these alternative learning opportunities.

We reiterate that there were several odds stacked against the students as they completed their projects described in this paper. Firstly, students in the three classes did not have the privilege of having a common meeting time because the classes were held at different times on different days of the week. Therefore, each student had to make significant changes in their personal schedule to make things happen. Secondly, the money available to complete each project was rather small, less than $\$ 75$ per project. Therefore, students had to conceive a project with the limited budget under consideration. Selected project teams were able to acquire free supplies through industry support and personal research. The authors feel that these learning experiences were invaluable and should augur well for students who proactively engaged themselves in these activities.

Learning and sharing from our preliminary experience, we urge educator teams keen on implementing interdisciplinary projects to plan the chain of events much in advance. Challenges and difficulties are to be expected. These projects require significant investment of faculty time and money for material and supplies used in constructing prototypes. Issues that arise with illstructured problem solving may not be received equally well by all students, however, our experiences were very positive. We believe that our initial planning and continued support extended to project teams helped things run as smoothly as they did. It is highly important that collaborating student teams have the opportunity to meet at a common time dictated by the scheduling of classes. Given this opportunity, it is highly probable that our students would have fared even better. We strongly advise that student project teams be required to submit a proposal during the initial weeks of the semester. Teams should also be advised to maintain a record of their meetings and activities. These instructions issued in a written format at the beginning of the semester served us well in communicating our expectations. Students should also be invited to rate their peers' performance in order to ensure a fair evaluation and encourage team participation. We used these peer evaluations in assigning individual grades. Students who were rated low by their peers received lower grades.

It should be noted that the tool used to assess this study is modeled from the standard end of semester student evaluation administered by the Department of Technology at NIU and is therefore not a proven research tool. There was no control group in this study and thus the results need to be interpreted with some caution. However, there are some general conclusions that can be drawn from the study. Firstly, the most important skill required for any team to function in a diverse engineering environment is communication skills. Secondly, any open ended design 
project will rely heavily on team members' ability to think creatively and critically. In an integrated product development environment, the product development cycle can be shortened drastically if team members engage proactively in critical and creative thinking. Team members who had excellent functionality had very positive learning experiences from each other and most suggested they would like to work in such an environment again. However for teams to work together effectively, they must be able to obtain common times that team members can meet. This study was done on students from three different classes and that met at different times and on different days, therefore it was not easy to get mutually convenient meeting times especially if a team had a student that was a full time employee elsewhere. From the results, it was also noted that teams that rated themselves low functionally expressed concerns about conflicts in meeting times. For the last fifty years, changes in the global markets and use of technology in manufacturing have augmented the need for team-based management in manufacturing. The norms and practices of simultaneous engineering must therefore be emulated for companies to remain competitive. The results of this study have shown how faculty can cooperate across courses to embed this important practice in manufacturing into a curriculum.

\section{Acknowledgment}

The authors acknowledge and thank all the students enrolled in TECH 414, TECH 420, and TECH 430T at Northern Illinois University during the Fall 2002 semester for completing the student projects described in this paper. The authors thank Dr. Teresa Wasonga of Northwest Missouri State University for the assistance provided in the area of statistical analysis. Last but not the least, the authors thank the 2001-2002 Committee for Improvement of Undergraduate Education at Northern Illinois University for providing their financial support to undertake this initiative.

\section{References}

1. Kasuba, R. (1996). Concurrent engineering as a blending agent for engineering and engineering technology education. In the World Congress of Engineering Educators and Leaders, UNESCO Conference Proceedings, Paris, France.

2. Manufacturing Education Plan: Phase I report. Industry identifies competency gaps among newly hired graduates. The Next step - Partnership with schools (1997). Manufacturing education for the $21^{\text {st }}$ century. Volume IV. Dearborn, MI: Society of Manufacturing Engineers.

3. Jeffries, M. J. (1991). Some aspects of industrial and academic change. Proceedings of the 1991 Conference on Frontiers in Education, West Lafayette, IN.

4. Kitto, K. L. (1997). Integrating concurrent engineering into undergraduate design and research experiences. Proceedings of the 1997 Conference on Frontiers in Education, Pittsburgh, PA.

5. Kara, S., Kayis, B. \& Kaebernick, H. (1997). Resources for new product development in Australia. Human Factors and Ergonomics in Manufacturing, 7(3): 237-249.

6. Azevedo da Silveira, M. \& Scavarda-do-Carmo, L. C. (1999). Sequential and concurrent teaching: Structuring hands-on methodology. IEEE Transactions on Education, 42(2): 103-108. 
7. Rozenfield, H., Aguiar, A. S., de Oliveira, C.B. M., \& Omokawa, R. (1998). Development of a concurrent engineering scenario for educational purposes. Proceedings of the International Conference on Education in Manufacturing, San Diego, CA.

8. Furukawa, Y. (1998). Manufacturing education in Japan. Proceedings of the International Conference on Education in Manufacturing, San Diego, CA.

9. Editor. (2001). Lead award honors manufacturing innovation. Manufacturing Engineer, 127(4): 126-132.

10. Finneli. C. J., Klinger, A., Budny, D. (2001). Strategies for improving the classroom environment. Journal of Engineering Education, 90(4): 491-497.

\section{Biographical Information}

DR. RADHA BALAMURALIKRISHNA joined the Department of Technology at NIU in August 1997. His undergraduate degree is in Naval Architecture and Shipbuilding from Cochin University, India. Dr. "Bala" has worked in a shipyard for three years and has taught engineering design graphics and CAD at the University level for nearly 10 years. He received his M. S. Eng. from Florida Atlantic University and Ph.D. from Iowa State University.

DR. ANDREW W. OTIENO received his Ph.D. from Leeds University, UK in 1994 and has been at Northern Illinois University since August 2000. His research is in the area of finite element modeling, machining processes, tool wear monitoring and structural health monitoring. He has experience in hardware/software interfacing with special applications in machine vision. He is a member of the ASEE and the SME.

DR. ABUL AZAD joined Northern Illinois University in 2001. Prior to that he was involved in teaching and research at the University of Portsmouth, UK. He also worked as electronics engineer in industry and research fellow at the University of Sheffield, UK. Dr Azad has extensive experience in modeling, simulation, design, development and control of engineering systems, which includes lightweight and mobile robots, vibrating structures and building energy management systems. He has about 60 papers in the areas of control theory and applications, mechatronics, and is active with professional bodies. While in UK, he was active in getting external funding from research councils, industries and other affiliated European agencies. 